\title{
Applications of computational fluid dynamics in optimisation and design of metallurgical processes
}

\author{
STEIN TORE JOHANSEN $\dagger$
}

Keywords: computational fluid dynamics, process technology, turbulence, granular flows, metallurgy

\begin{abstract}
During the last two decades computational fluid dynamics (CFD) has become a powerful tool for analysing and designing metallurgical processes. In this paper we give examples on how these techniques can be applied to a large variety of processes and also how CFD can be used to predict heat and mass transfer from fundamental principles.

The paper is restricted to the applications of CFD at SINTEF Materials Technology. The examples given in the paper will range from treatment of raw materials, environmental issues, furnace processes and combustion, magnetohydrodynamics, melt treatment and casting.
\end{abstract}

\section{Introduction}

In a large number of metallurgical processes transport and exchange of charge, mass, momentum and energy is of critical importance to the outcome of the process. The most visible of the metallurgical transport processes are easily identified during the route starting at the breaking of mineral ores, followed by mineral dressing, raw materials processing and refining, transport and handling of raw materials, liquid metals production, casting of metals and cleaning and energy recovery of waste gases. In this chain of processes we find a huge tonnage of materials which are moved, transformed and refined by different methods. Fundamental and characteristic to almost every such process is the flow of materials. We may be dealing with both granular flows (discrete particles), single phase fluid flows (continua of liquid or gas) or as most often complex multiphase flows (metals, dissolved elements, slags, solid phases, gas bubbles, inclusions) where many phases interact simultaneously.

Due to the complexity of such processes the most accepted route to the development and optimisation of a metallurgical process has traditionally been a combination of process experience, simplified analytical and numerical calculations and trial and failure. However, there has been a large number of surprises during the years, especially during scale-up of processes to production plants.

Today new tools are offered to the process metallurgist. The introduction of faster and cheaper electronic computers has opened up for a much more detailed analyses of the metallurgical transport processes. As a consequence a large research field has grown up. The most common name for this field is "Computational Fluid Dynamics" (CFD). The key element in this field is to solve the fundamental equations representing the fluid flow in a discrete numerical form by a computer. In the same manner conservation equations for all definable quantities may be formulated and predicted. The value of

$\dagger$ SINTEF Materials Technology, N-7034 Trondheim-NTH, Norway. email: steinj@mail.trd.sintef.no.

An early version of this paper was presented at the SIMS '96 Applied Modelling and Simulation Conference, Trondheim, Norway, June 11-13, 1996. 
the prediction is of course strongly coupled to the precision and quality of the physical descriptions in the model.

A large number of persons has contributed to the development of "Computational Fluid Dynamics". The introduction of the $k-\varepsilon$ turbulence model by Harlow, Launder and Spalding (1972) made it possible to do engineering calculations of turbulent industrial flows. Together with the numerical techniques presented by Patankar (1980) and the freely distributed TEACH-code from Gosman (1976) it became possible for metallurgists to do CFD-calculations.

In this context we will like to mention B. D. Spalding which has been a forerunner in the application of CFD to industrial processes. In the field of metallurgy the late $\mathbf{J}$. Sekely has taken a similar position.

At SINTEF Metallurgy, the field of CFD started up in 1984. Since that time we have been studying a significant number of very different processes and we feel that these tools have a large potential both in an economic and environmental perspective. In this paper we would like to share some of our experiences and hopefully give some guidelines for applying and further developing these tools.

\section{The theoretical framework of CFD (Computational Fluid Dynamics)}

In general CFD models may be formulated in both an Eulerian or a Lagrangian framework. In the Eulerian framework the models are formulated on control volumes fixed in space. This concept is in our research group used in general for all conserved field quantities. However, in the case of dispersed multiphase flows the Lagrangian concept may be prefered due to its generality. In Lagrangian based simulations the position and velocities of individual particles or bubbles are computed. The fundamental transport equations in CFD are the Eulerian conservation equation for mass:

$$
\frac{\partial}{\partial t} \rho^{k}+\frac{\partial}{\partial x_{j}}\left(\rho^{k} U_{j}^{k}\right)=R^{k}
$$

Here the superscript $k$ is a phase indicator (slag, gas bubbles, inclusions etc.), $\rho^{k}$ is the volumetric density, $U^{k}$ is the mass averaged velocity and $R^{k}$ is the mass source due to mass transfer or chemical reactions. Newton's second law gives us the Eulerian momentum conservation equation:

$$
\begin{aligned}
& \frac{\partial}{\partial t} \rho^{k} U_{i}^{k}+\frac{\partial}{\partial x_{j}}\left(\rho^{k} U_{j}^{k} U_{i}^{k}\right)=-\frac{\partial}{\partial x_{j}} p^{k}+\frac{\partial}{\partial x_{j}} \tau_{l i j l}^{k} \\
&+\sum_{l=1}^{N} K_{i}^{k l}+\rho g_{i}+F_{\text {extern.. } i}^{k}+U_{i}^{k} R^{k}
\end{aligned}
$$

Here $p^{k}$ is the total internal pressure in the actual phase (marked $k$ ), $\tau_{i j}^{k}$ is sum of the molecular controlled and turbulence controlled shear force, $K_{i}^{k l}$ denotes the interfacial momentum exchange, $g_{i}$ is the acceleration of gravity and $F_{\text {extern.. } i}^{k}$ is the body force due to other external forces (electromagnetic force etc.) than gravity. Equations (1) and (2) may be employed on a large number of industrial problems if we can describe the physical situation in terms of models for $R^{k}, \tau_{i j}^{k}, K^{k l}$ and $F^{k l}$.

In addition to (1) and (2) we need the conservation equation for energy, represented by the enthalpy, and conservation of the mass of dissolved species. These equations are not presented here.

If we decide to use the Lagrangian formulation for particles or bubbles the particle trajectories are calculated from: 


$$
m_{p} \frac{d}{d t} V_{i}=R_{i}+m_{p} g_{i}+f_{\text {exter. } i}
$$

where $V_{i}$ is particle velocity, $m_{p}$ is particle mass, $k_{i}$ is the forces caused by the surrounding fluid and $f_{\text {exter. } i}$ is external body forces (not gravity). The particle position $X_{i}$ is calculated from:

$$
\frac{d}{d t} X_{i}=V_{i}
$$

By using the "Particle Source in Cell" concept due to Crowe (1977) we may account for the both-way coupling between particles and the continuous fluid. The effects of different forces acting on particles and bubbles, including turbulence effects, has been discussed in previous works (Johansen 1990).

\section{Numerical tools and experimental verification}

Today a large number of commercial computer programs have become available for CFD simulations of industrial processes. A significant number of these programs have a high standard and have proved to be useful tools. In our group we have concentrated on the CFD-code FLUENT ${ }^{(\mathrm{tm})}$. This is one of the codes which is based on Patankar's numerical schemes (Patankar 1980). The code was supplied to us with full source code and we have been able to build our models into an existing professional framework. The bulk of the work which will be presented in this paper would not have been possible without access to the full FLUENT source-code. In this respect we worry about the claimed future trend that fewer and fewer CFD-codes will be available in source-code.

\subsection{Classification of mineral particles}

CFD was originally used by us to understand the flows in centrifuges and cyclones. The purpose of this research was to construct new devices for gas cleaning. By combining centrifugal forces and the thermophoretic forces due to strong temperature gradients we were able to show (Johansen and Andersen 1986) that by combining these two principles quite remarkable improvements in removal efficiencies may be obtained.

Quite unconventional centrifuge designs were also tested in CFD computations (Venås and Johansen 1986). These simulations led us into classification of particulate materials coming from grinding mills. The materials can be minerals, plastics or even metals. In this process the flow of powder from a mill is continuously fed into a classifiers. The purpose of the classifiers is to take out from the powder stream as much as possible of the particles below a given size. In addition the fine fraction or the product should be free of large particles. Since the classifiers are flow devices CFD tools have been found extremely useful for understanding and optimising such devices (Johansen and Silva 1989, 1994). A special multi-fluid model was developed to investigate classifiers (Johansen, Anderson and de Silva 1990). In this model 5 particle size classes were included and the particles were allowed to interact both with the mean flow and the turbulent structure in the device.

Fig. 1 shows the outline of the ACUCUT Classifier. This rotor-based classifier was studied in 2 and 3-dimensional calculations. Fig. 2 shows a horizontal cut (2D calculation). From these simulations the importance of the initial gas rotation into the classifier was revealed and we were able to explain why the flow very easily may separate and give strong degradation of classification performance. By implementing a special numerical technique for a rotating frame of reference (Dong, Johansen and 


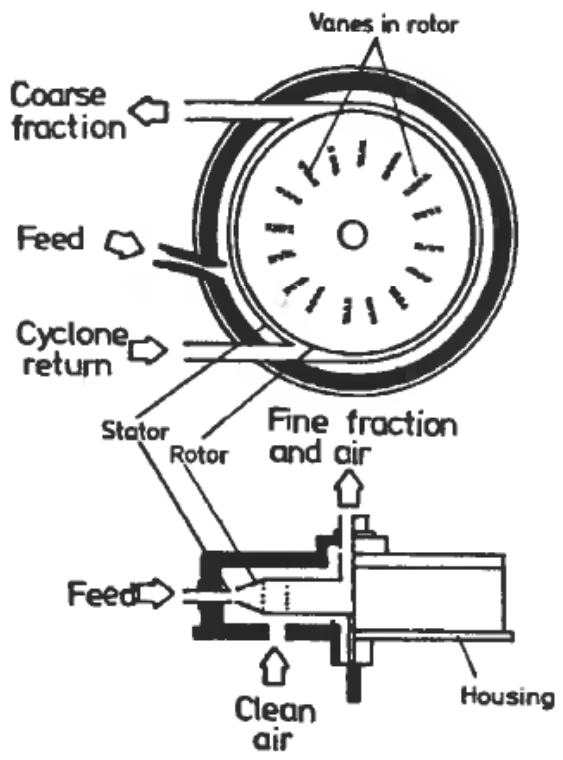

A Forced Vortex Classifier

Figure 1. The ACUCUT Classifier (Johansen and de Silva 1994).

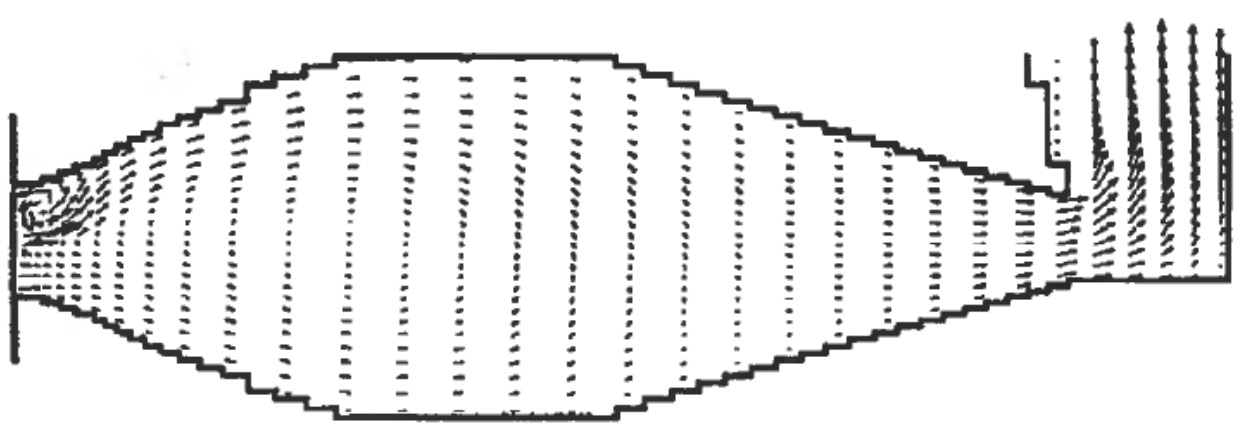

Figure 2. Predicted velocity vectors in the ACUCUT Classifier (Johansen and de Silva 1994).

Engh 1994) 3D simulations of the ACUCUT classifier became possible. From the model developed in reference (10) we could compute grade efficiency curves which could be compared to experimental data. In Fig. 3 we see predicted grade efficiencies for the ACUCUT Classifier based on 2D and 3D simulations. The top size seems to be well represented in the extremely simplified $2 \mathrm{D}$ simulations.

In a similar manner we investigated $10 \mathrm{~mm}$ diameter hydrocyclones (Johansen, de Silva and Vesanto, 1990). Here we found again that CFD tools could provide insight into the cause for detrimental secondary flows in the washing-section of the classifier. Fig. 4 shows the predicted streamlines and profiles of the tangential velocity. Fig. 5 shows predicted grade efficiencies compared to experimental data. It was also concluded that $k-\varepsilon$ turbulence models were completely inadequate for these flows and that we had to resort to Reynolds-Stress models in the case of free vortex flows. The simulations led to considerable improvements in the design of the hydrocyclone as the loss of product (fines) to the washing stream was reduced. 


\section{ACUCUT Grade Efficiency}

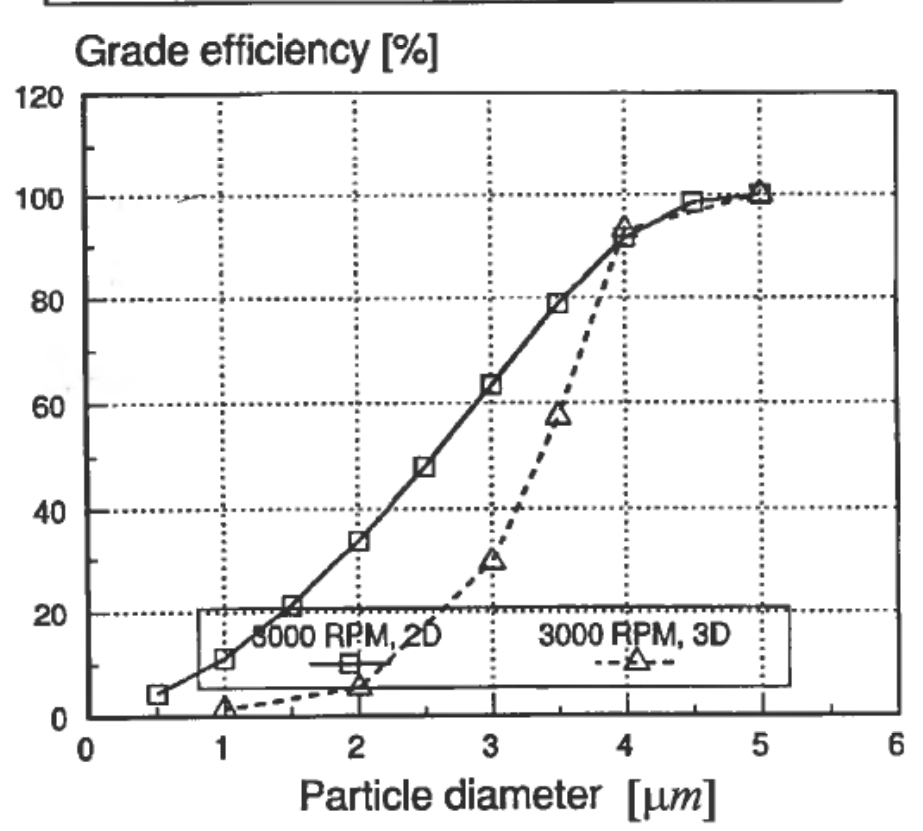

Figure 3. Predicted grade efficiencies for the ACUCUT Classifier (Johansen and de Silva 1994).

\subsection{Design of unloading system for alumina powder from ships}

During unloading of ships by grabs the content in a grab was emptied into a hopper. As this was taking place in the open air, fine dust particles were taken by the wind and carried over large distances. These led to dust pollution problems in the neighbourhood of the plant. At the Elkem Aluminium's plant at Lista, Norway, it was decided to improve on this situation. A typical scenery from Lista is seen in Fig. 6. In this study major parts of the multi-fluid model from Johansen, Anderson and de Silva (1990) was developed. The model was intended to reproduce the transient physics in the dusting problem. When a grab containing 6 tons of alumina powder is opened very strong gravity driven flows are created. The gas flow resulting from the falling powder has sufficient momentum to return significant amounts of fine dust particles back into the open atmosphere. In this project we co-operated with G. Enstad, POSTECH. In their laboratory a laboratory model in size 1:5 was built. In the numerical model, the existing situation was simulated both in full scale and in lab-scale. In Fig. 7 we see powder concentration and gas velocity vectors 1.5 seconds after the grab was opened just after it was emptied. From the calculations it was clear that by sucking off the correct amounts of gas inside the hopper during filling, the dust problem could be strongly reduced. A new hopper with gas suction was designed in the computer and the solution was tested in lab-scale. The agreement with computer model results for the new lab-scale design was satisfactory. Based on these results we designed the new full scale hopper, gas suction channels and decided the fan capacity. Even the dust capacity for the filters which took care of the previously lost alumina was designed from the CFD model and the lab-scale results. 

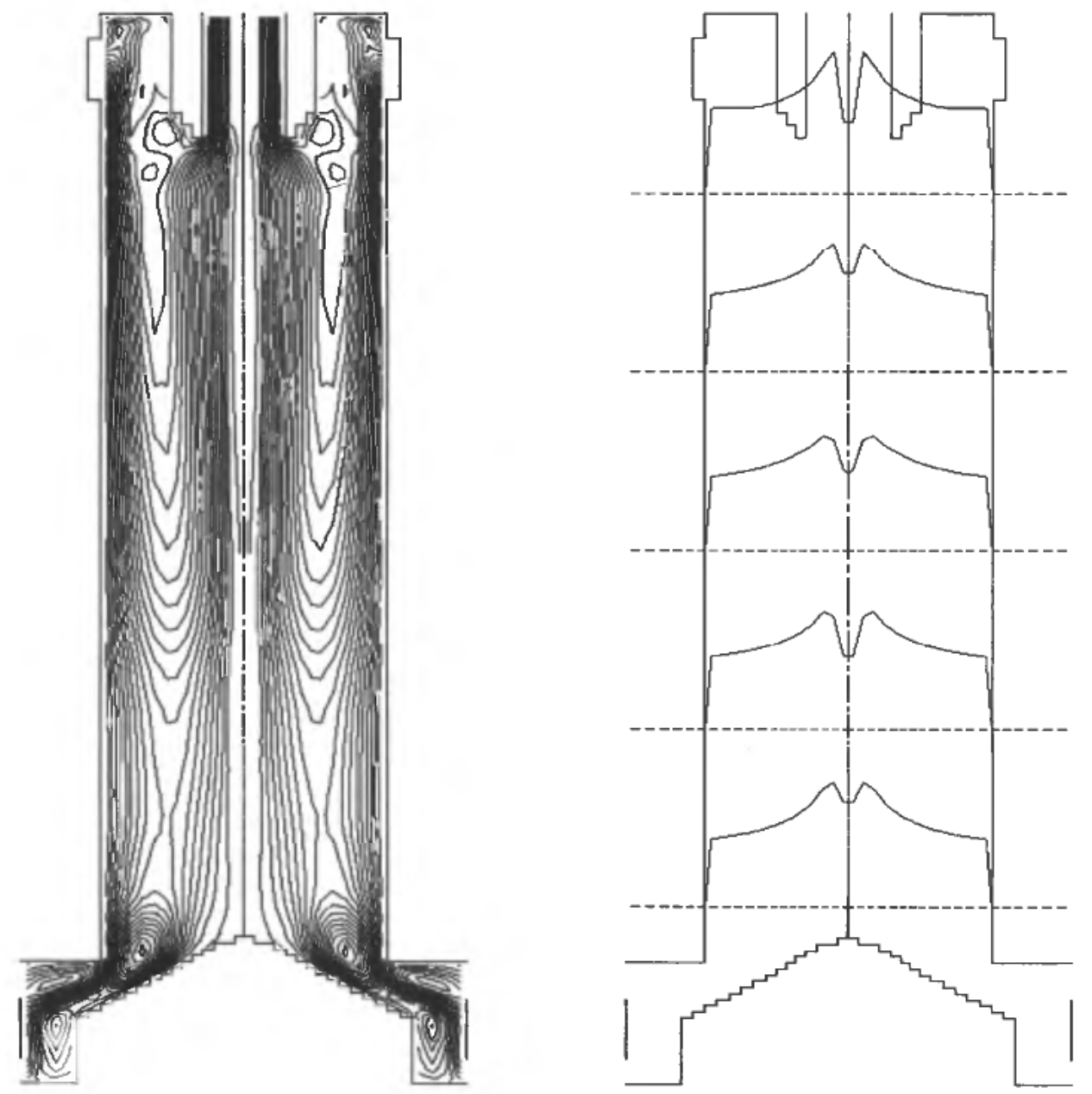

Figure 4. Predicted streamlines (left) and tangential velocity profiles (right) for the TC-10 hydrocyclone (Dong, Johansen and Engh 1994).

The result was successful and the goal of reducing the emissions by more than $80 \%$ was met without problems.

\subsection{Bulk powder systems}

During transport of particulate raw materials phenomena like breaking (size degradation) and segregation may take place. In addition the description of the particulate flow rheology is extremely complex. We are quite optimistic on the possibility to come up with models which may describe these phenomena. In the model referenced above (Johansen, Anderson and de Silva (1990)) there was no description of the bulk powder flow. When this model was applied to air induced segregation in a silo we found initially that the prediction were in good agreement with experimental data (Enstad 1992). However, the agreement became poorer and poorer as the heap at the bottom of the silo became higher. A prediction of the relative radial concentration of different sizes in the silo is shown in Fig. 8. When a heap forms inside the silo the flow along the heap surface cause additional segregation and our model had no physics to 


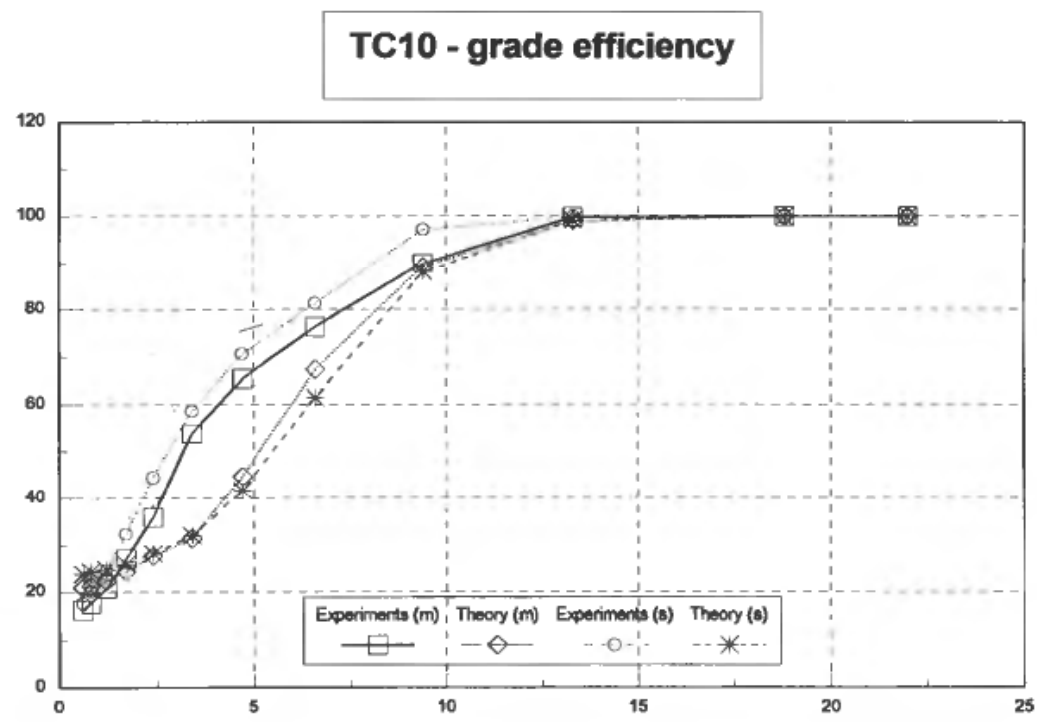

Figure 5. Predicted and experimental grade efficiencies for the TC-10 hydrocyclone (Dong, Johansen and Engh 1994).

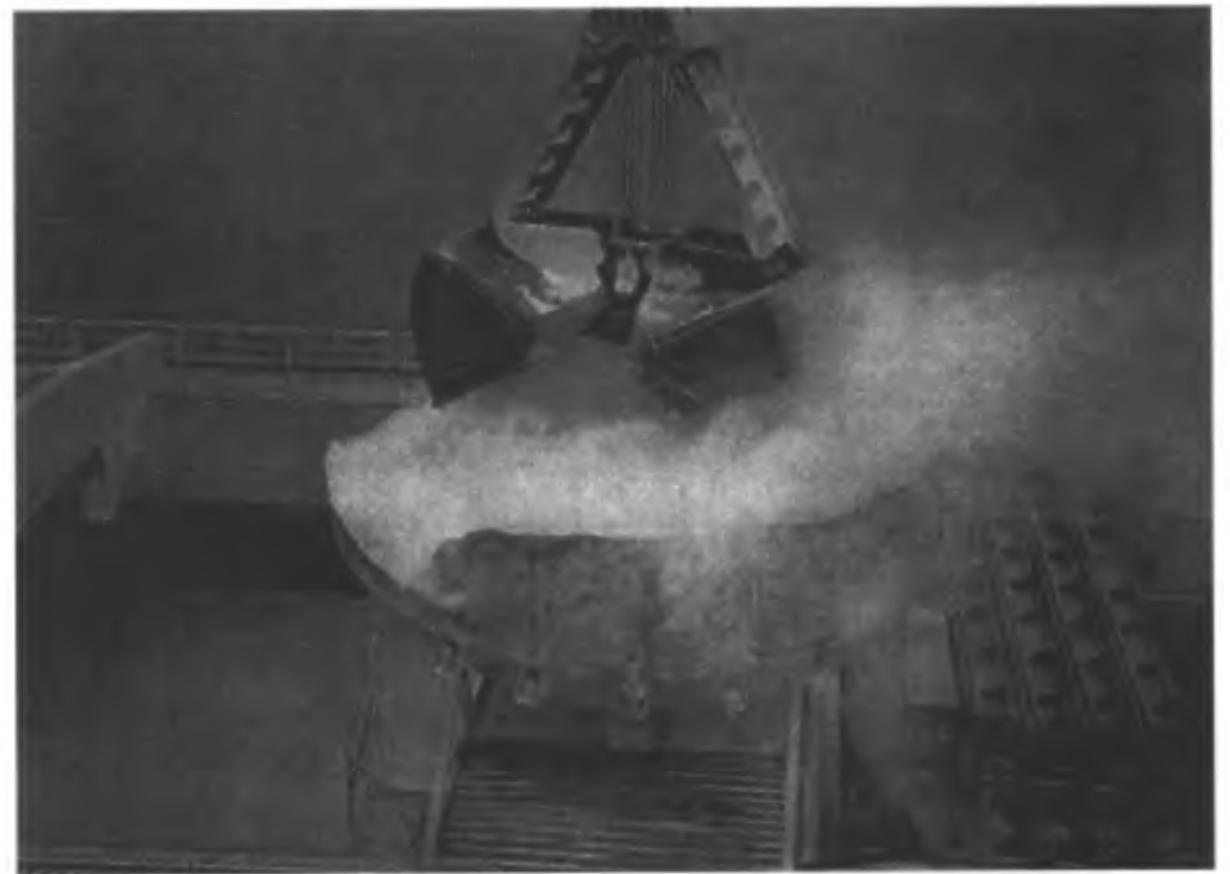

Figure 6. The original dusting of fine alumina particles from the Elkem Aluminium plant at Lista.

accommodate these phenomena at that time. However, the model could explain to us how the gas flow inside the silo has a tendency to distribute the finer particles more evenly over the entire silo surface, while the larger particles end up in the centre. This picture is of course altered by the solids flow on the heap surface.

More recently we developed a new mathematical-numerical model which has made 


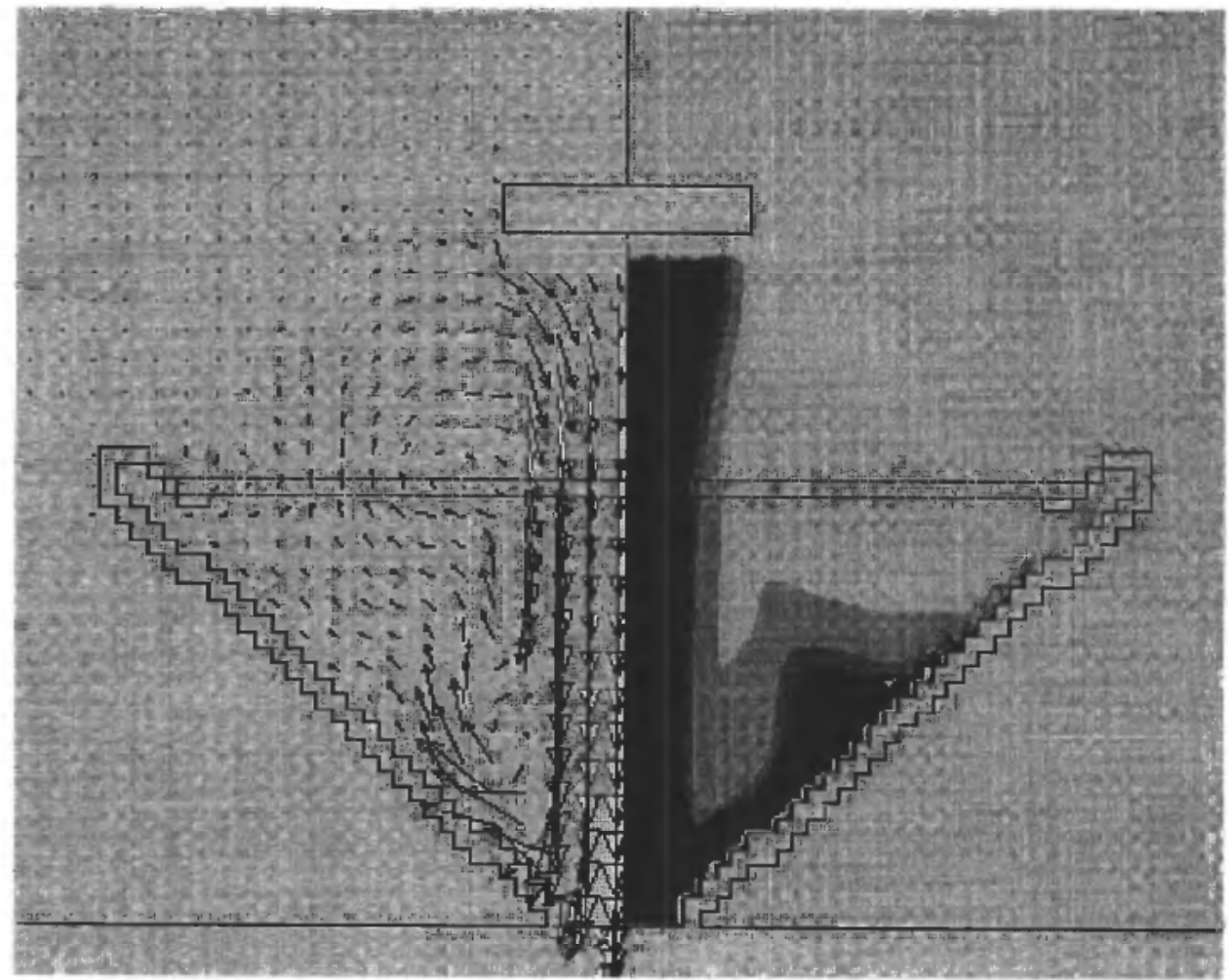

Figure 7. Predicted velocity vectors (left) and alumina powder concentration (right) 1.5 seconds after start of filling.

it possible to model gas-solids mixtures at any concentration (Johansen and Laux 1995). In this model the solids are described by a kinetic approach which is similar to the kinetic gas theory. At a completely compacted state the stresses in the powder is assumed to be similar to the situation in soil mechanics (Johansen and Laux 1995). When this model is applied to flows in hoppers we get excellent agreement with available experimental correlations (Laux 1997).

In Fig. 9 we see a snap-shot of the predicted concentration of solids, the gas velocity and the powder velocity in an hour glass.

We are also applying these models (Johansen and Laux 1995) in order to understand the flows and mass-exchange in fluidized beds. In Fig. 10 we see the time averaged predicted gas volume fractions compared to the experimental data (Laux 1997). It is evident that this type of model can shed light on important features in fluidized beds and that this type of CFD-models can be applied to industrial design. However, the inclusion of segregation phenomena in this class of models is not straightforward. A future challenge here is the formulation of the partial pressures, or stresses, in a polydisperse mixture of particle sizes.

\subsection{Furnace design, combustion and off gas treatment}

In metallurgical processes the mass flow and heat transport inside the furnaces are of particular interest. Above the top surface of the furnace combustion processes may take place. In addition particulate solids may result as a reaction product. Fine particles from the off gas (reaction products) or fluidized particles from the raw materials are 


\section{Air-induced segregation in a silo}

Relativ distribution for different

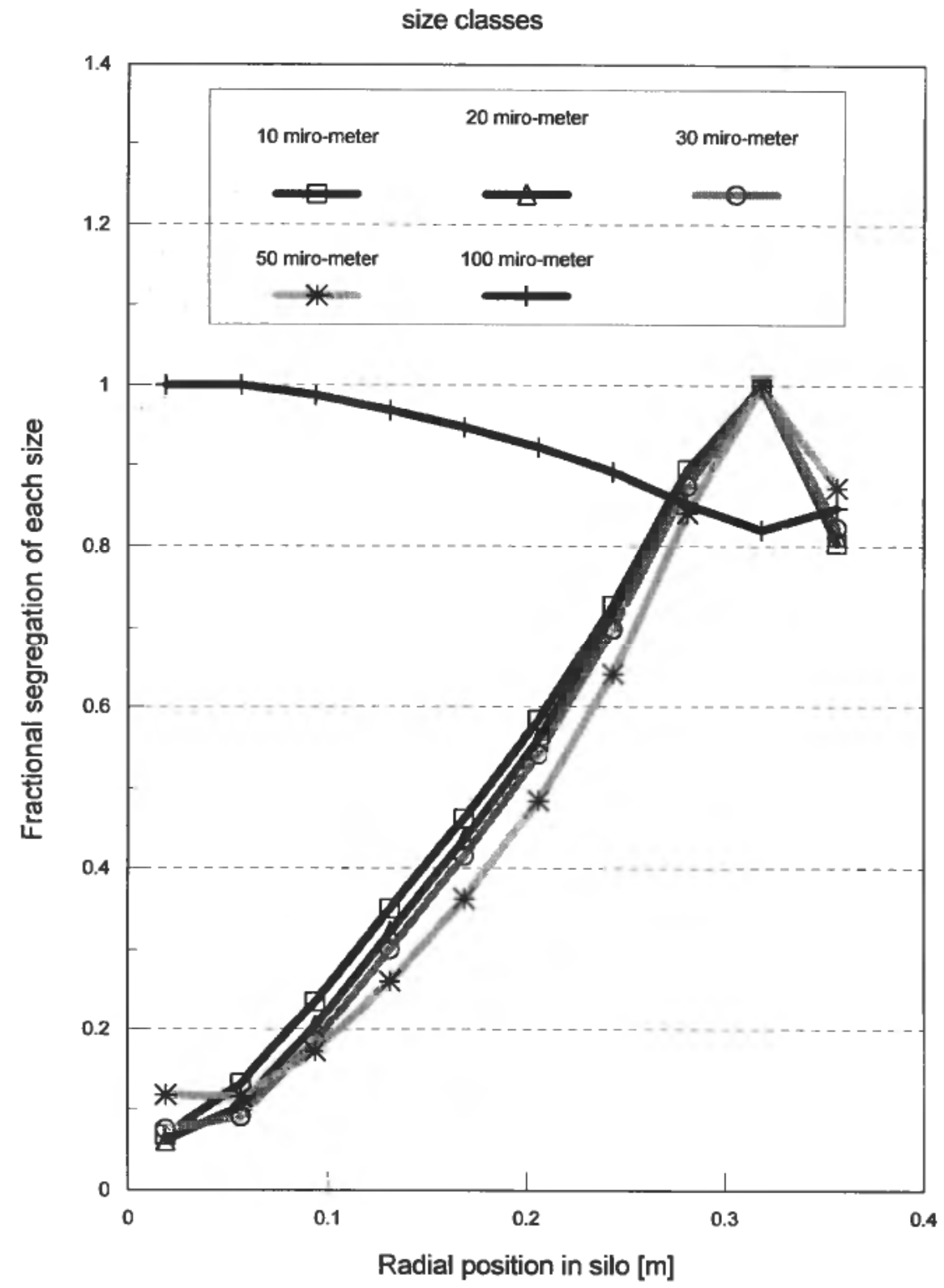

Figure 8. Predicted relative distribution of different size-classes of alumina powder in a silo.

transported by the off gas and may deposit on channel walls in given areas and under given conditions. Here we see a large number of industrially interesting situations which may be analysed in great detail by CFD models.

In aluminium reduction cells the anode gas creates bubbles which has a strong impact on flow and mass transfer in the electrolyte. We analysed these phenomena for the first time in 1989 (Solheim et al. 1989). The gas bubbles were here treated as 

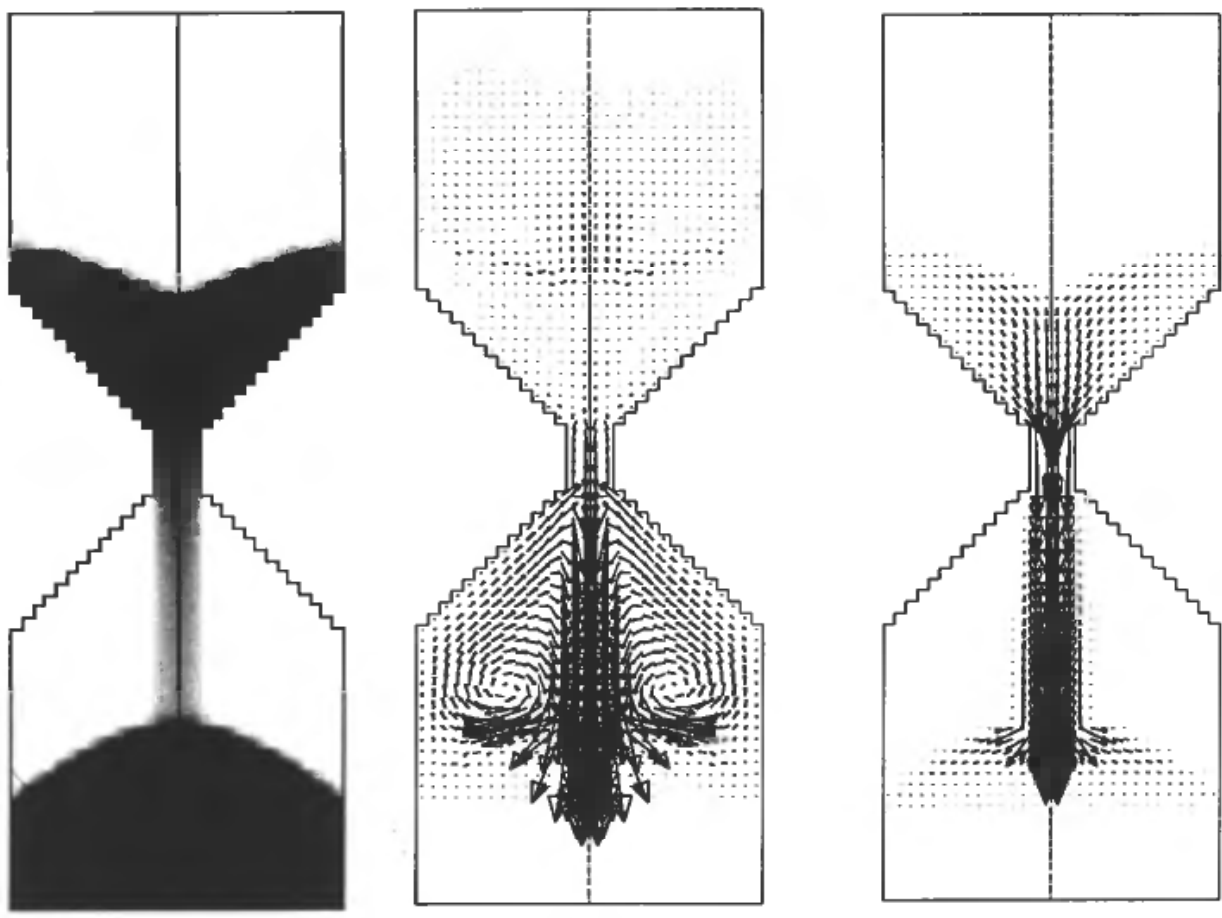

Figure 9. Predicted flow in an hour-glass. Left solids concentration, middle gas velocity and right powder velocity (Laux 1996).

Lagrangian "particles", exchanging momentum with the electrolyte. A typical bubble driven flow-field under the anode and in the side channel is seen in Fig. 11. The CFD model was able to predict experimental velocities, measured by residence time experiments, to within 15\% (Solheim et al. 1989) These results included a set of 9 different experimental conditions. The CFD model could here tell us that the depth of immersion of the anodes would strongly effect the flow in the electrolyte as well as the metal loss (current efficiency). We also found that the flow in the metal pad, which is driven by electromagnetic forces, had a minor effect on the electrolyte flow.

When the anode gas, originating as $\mathrm{CO}$ bubbles, leaves the electrolyte, this is a combustible gas. This brings us to the special field of turbulent combustion. Here a good CFD model will rely on an accurate description of turbulence as well as an accurate and robust model for the turbulence enhanced reaction rate. Attempting to address these fundamental problems we proposed a new model for turbulent combustion (Gammelsæter, Johansen and Bergstrøm 1991) which explore a mixture of moment closure and probability density functions. This model was then used to predict the combustion of CO-gas in a burner at an aluminium Søderberg cell. Predicted CO out from the burner is compared to experimental data in Fig. 12. This model was then successfully applied in the design of new burners which has proven to be much more efficient than previous designs (Gammelsæter 1996).

Above the furnace the waste-gases are transported to a filter and in the most advanced plants the hot, dusty gases are heat exchanged before they reach the dust filter. These heat exchangers are specialised boilers for production of steam for generation of electric power. In this case off gas temperatures are high (more than $700^{\circ} \mathrm{C}$ ) and clogging of the off-gas channels may become a serious problem. We attacked this 

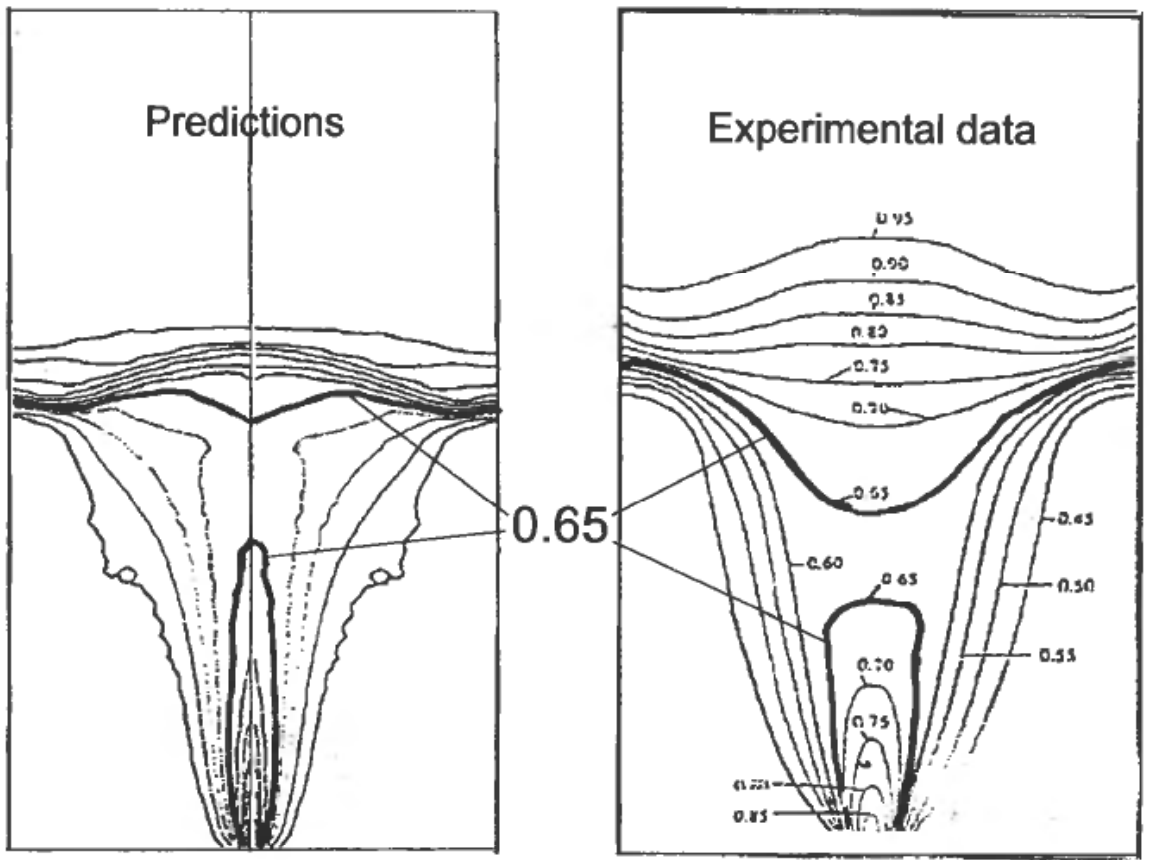

Figure 10. Porosity in a 2-dimensional fluidized bed. Iso-curves for $65 \%$ gas volume fraction is indicated by thick lines (Laux 1997).

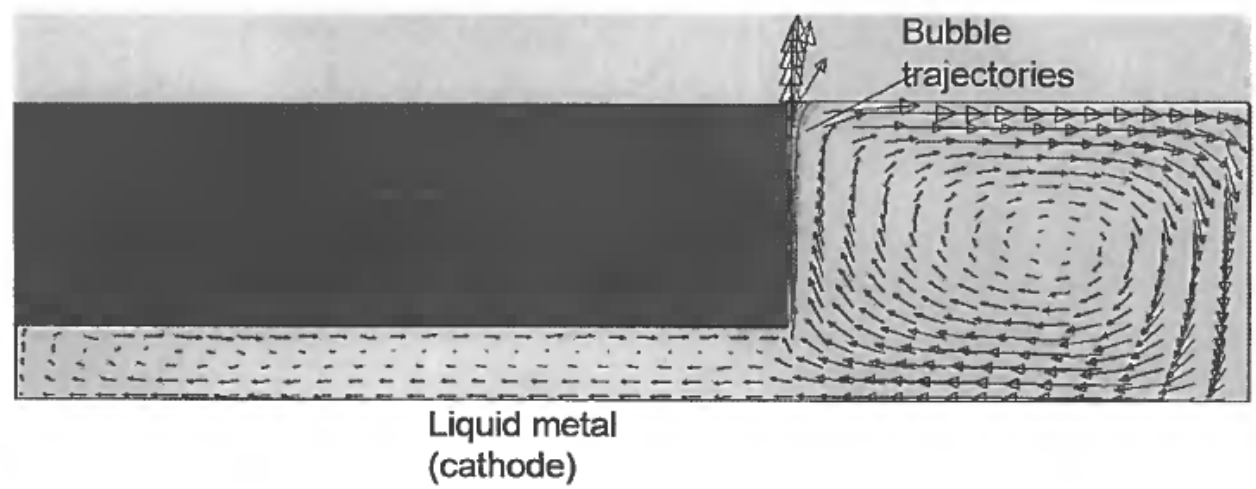

Figure 11. Flow pattern in the interpolar gap (electrolyte) of an aluminium reduction cell (Solheim et al. 1989).

problem by combining extensive experimental investigations by CFD modelling (Johansen et al. 1991). In addition localised CFD models for particulate transport in turbulent boundary layers was developed (Johansen 1991) and the effect of thermal gradients combined with particle inertia and turbulence was discussed in special (Johansen 1991). These studies resulted in a significant number of discoveries. By Lagrangian simulations of the flow of raw material particles the fines from the raw materials were found to be one major source to the problem. In addition the models showed that the design of furnace room, off-gas channel entry, channel cross-section and channel wall temperatures all had significant impact on the deposition and the clogging. The actual furnace under study has two off-gas channels and the CFD-model showed that when one of three side ports are open for stoking and furnace maintenance 


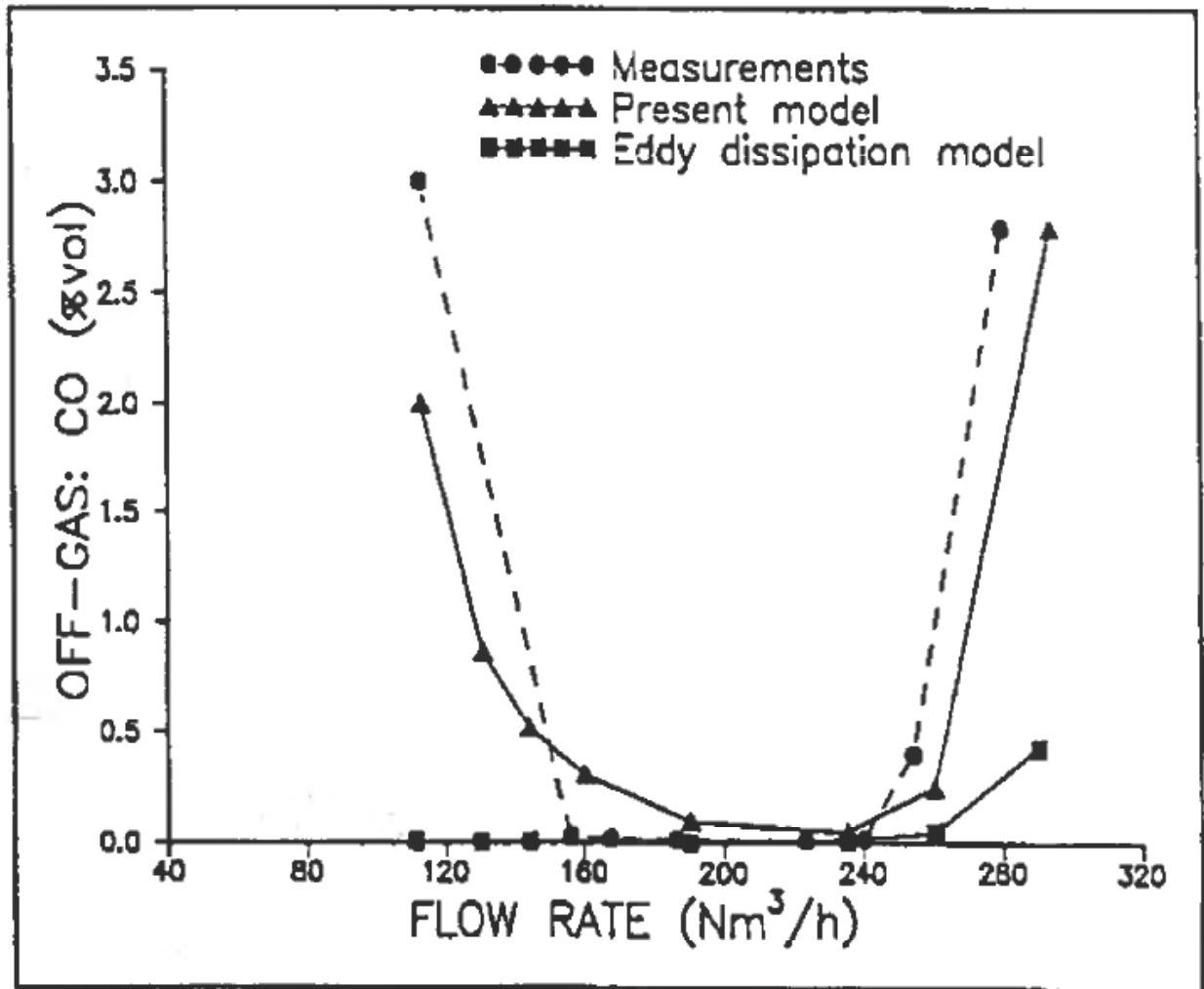

Figure 12. Predicted emissions of $\mathrm{CO}$ gas from a burner versus flow rate of air through the burner (Gammelsæter, Johansen and Bergstrøm 1991).

the flow field inside the furnace becomes extremely asymmetrical. Fig. 13 shows the situation during furnace maintenance. We see a strong segregation of temperature. The cold air coming through the open port gets into the closest off-gas channel. At the rear channel we see extremely hot combustion products from the furnace gas (Johansen 1993). This unexpected temperature segregation was found to accelerate the clogging rate as the wall deposits formed melt phases during periods of extremely high temperatures. By imposing a symmetrical situation during maintenance the clogging was significantly reduced (Johansen 1993).

\subsection{Magnetohydrodynamics for metal production and synthesis of materials}

CFD can also be applied to investigate fluid flows driven by electromagnetic fields. This special branch of CFD (Magneto-Hydro-Dynamics) has a large number of applications in processing of materials. In our group there has been a significant activity on developing CFD-models for thermal plasmas. This activity, led by Professor J. A. Bakken, has led to simulation models for industrial processes (Gu 1993) including both gas phase and metal phase flow, studies of 3-dimensional torches (Holt, 1994), the flow and chemistry in Si-furnaces (Andresen 1995) and time dependent simulations of free burning AC arcs (Larsen et al. 1995).

In our general purpose CFD-code FLUENT we implemented a generalised model for analyses of flows in liquid metals (Johansen 1994). Here, we assumed that the magnetic field was induced by two sources, internal and external electric currents. 


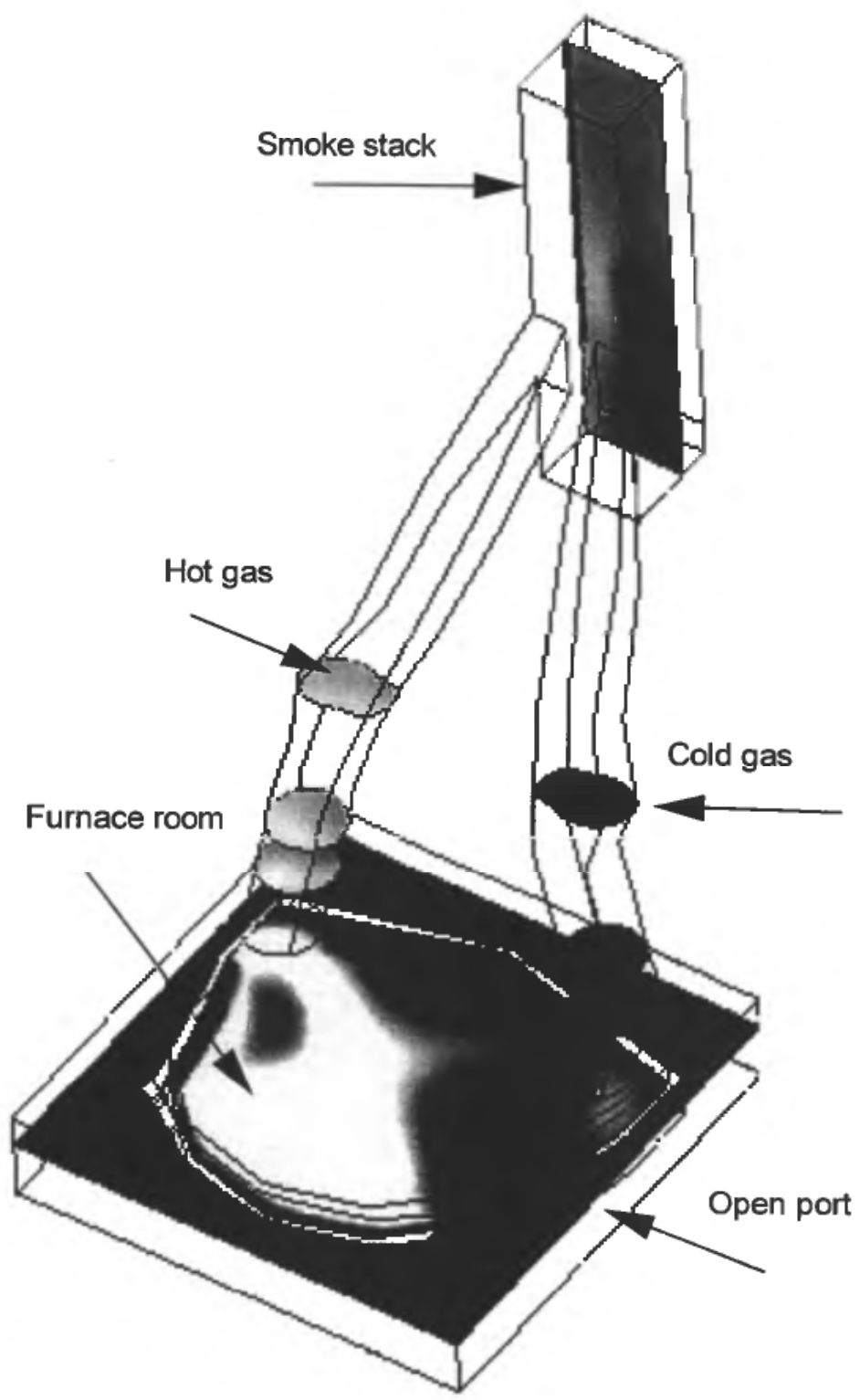

Figure 13. Predicted temperature distribution at Furnace II, the Elkem FeSi plant at Thamshavn. Black regions are below $900 \mathrm{~K}$ and white areas are above $1700 \mathrm{~K}$.

Hence, induction phenomena due to the flow itself can be captured. A typical example is seen in Fig. 14 which show the flow through a narrow slit in a channel under influence of a transversal static magnetic field (Johansen 1994). The actual flow pattern is caused by the magnetic force caused by the induced currents.

This type of model has been applied to studies of the flow pattern, heat and mass balance in reduction cells for aluminium production. In some cases the magnetic fields has a pronounced effect on the structure of turbulence. Then the transport of mass and heat is significantly altered and we need to improve the turbulence models. In an attempt to describe some of these effects we proposed a Reynolds stress turbulence model for 

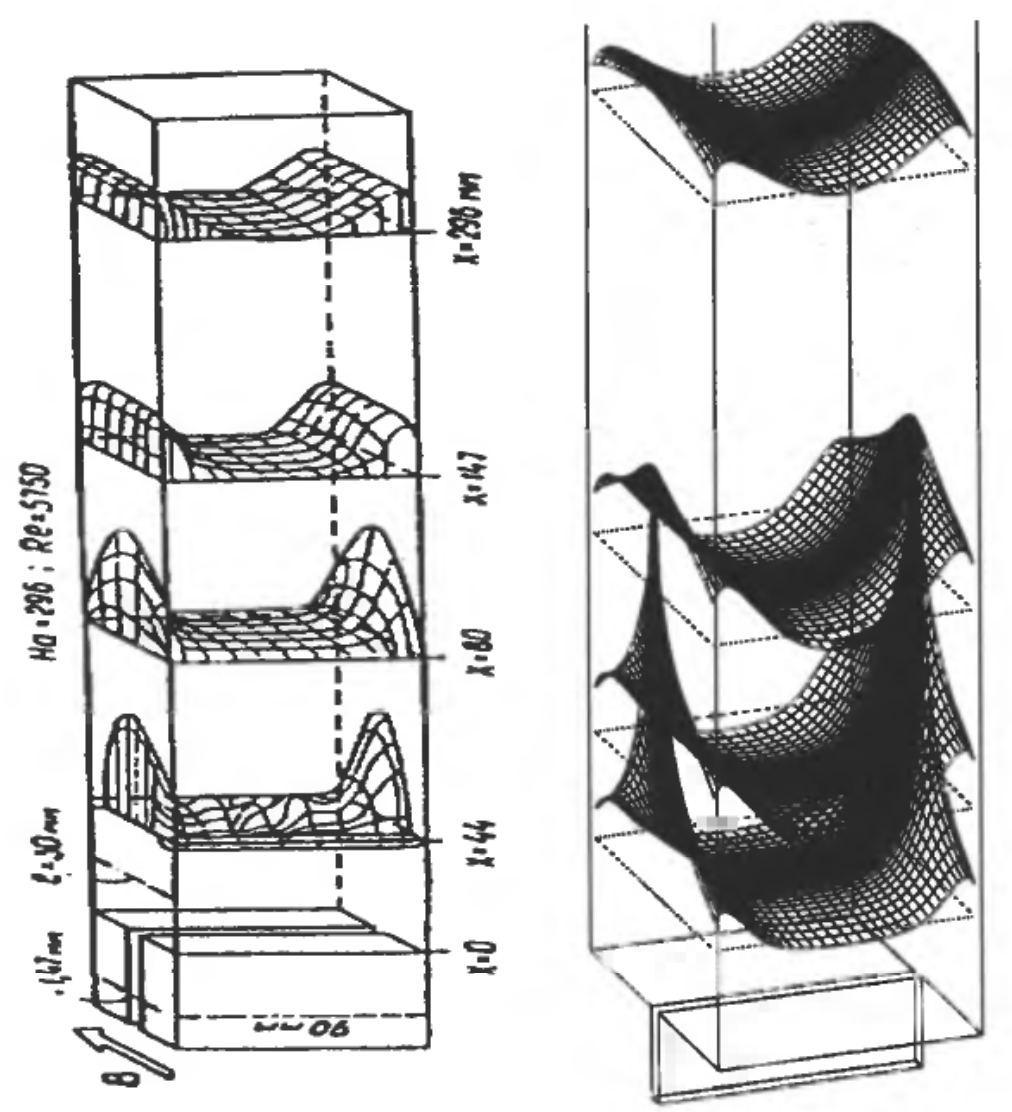

Figure 14. Experimental velocity field of mercury flow through a slit, influence by a horizontal, transverse magnetic field (above). Prediction by CFD is shown below (Johansen 1994).

MHD flows (Johansen and $\mathrm{Gu}$ 1994) This type of model is important in order to understand the surprising transport phenomena found in these flows.

Everybody should keep in mind that CFD tools can only predict the behaviour of a process if the theoretical formulation is able to describe the physics and chemistry in the process under study.

\subsection{Melt refining and alloying}

One metallurgical field that has many applications for CFD is melt refining. The melt flow pattern, heat transport, mass transport, bubble behaviour and inclusion transport can be studied to great details. When we started CFD studies of bubble driven flows in steel, aluminium and water models (Boysan and Johansen 1985; Johansen, Boysan and Engh 1986; Johansen, Boysan and Ayers 1987; Johansen and Boysan 1988) the bubble movement was studied by the Lagrangian technique. The force interaction between bubbles and liquid was calculated by the Particle-Source-in-Cell technique of Crowe (1977). We were able to reproduce experimental data well both in liquid metals and in steel. We computed the flow field for four different gas flow rates in the water model and the CFD model reproduced well both the localised velocity distribution and the effect of varying flow rate (Johansen and Boysan 1988). In the paper only the results for the lowest and largest flow rate are shown. When the same model was applied to 

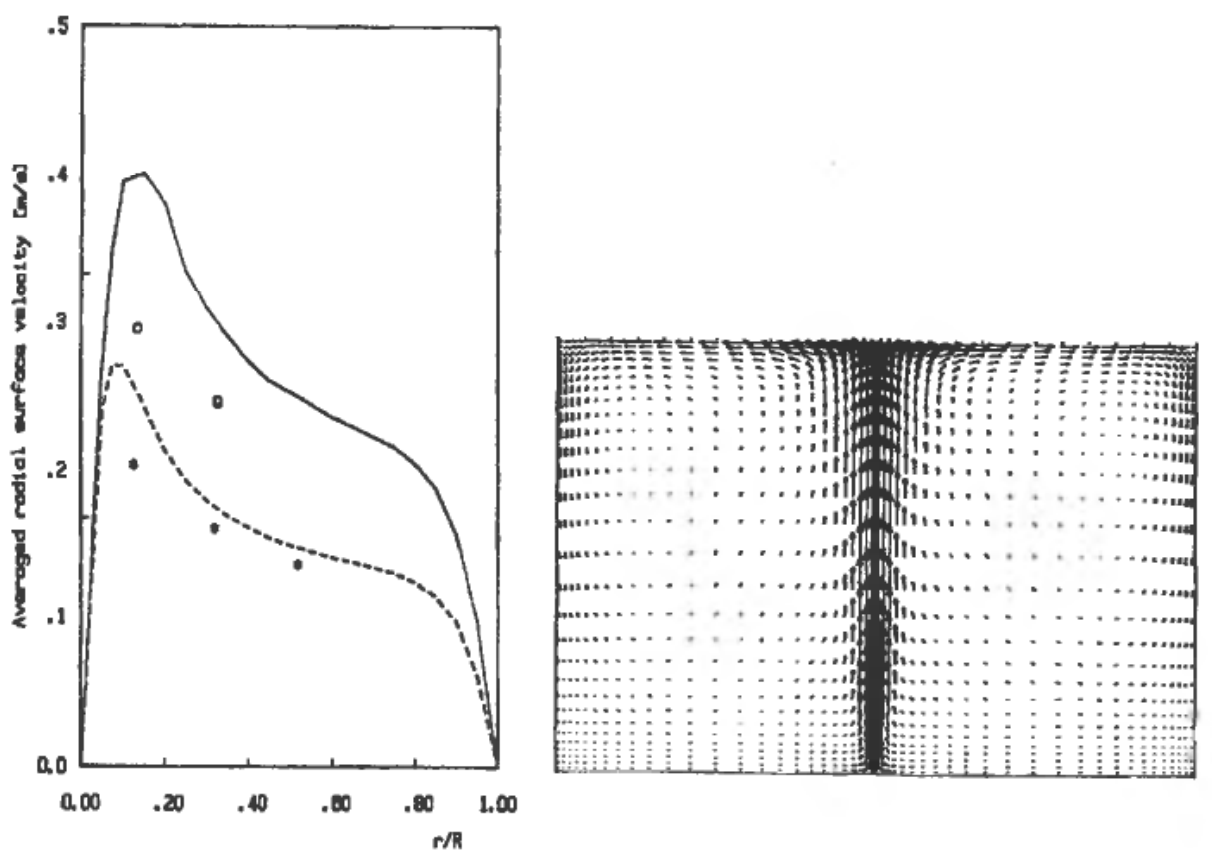

Figure 15. Predicted near surface radial velocities in a 60 ton steel ladle are compared to experimental data to the left (two gas flowrates). To the right we see a typical prediction of the velocity field (Johansen, Boysan and Engh 1986).

the flow in a gas purged steel ladle, similar good results were obtained (Johansen, Boysan and Engh 1986). In Fig. 15 we see the predicted velocity field for a 60 ton steel ladle and a comparison with the radial near surface velocity distribution (Johansen, Boysan and Engh 1986). As far as we know this is the only paper in the literature which has compared CFD results on gas purging with measurements in an industrial scale steel ladle.

The CFD-technique has further been applied to improve and provide physical understanding of the special impeller named the "Hydro-Aluminium Rotor" designed for melt cleaning of aluminium. In Aarflot, Johansen and Venås (1992) it is given examples on how CFD results were applied in the development of the melt cleaning unit built around this impeller. In a more recent paper (Hop, Johansen and Rasch 1996) we have tried to develop theories for the turbulent and centrifugal deposition (flotation) to the purge gas bubbles. By calculating both the flow field and the individual bubble trajectories the local effects (local melt rotation and turbulence) may be accounted for and global inclusion removal rates can be predicted.

The predicted flow field and bubble trajectories for the "Hydro Aluminium Rotor" are shown in Fig. 16. The predicted removal rate of artificial inclusions (SiC-particles) in aluminium is compared to experimental data in Fig. 17. In this work effects of inclusion agglomeration are neglected.

The micro models for particle deposition to bubbles were investigated by flow calculations around spherical objects ("bubbles") which fulfilled rigid-surface and shear free surface boundary conditions. The predicted capture efficiencies (Johansen, Fredriksen and Rasch 1995) were in good agreement with analytical theories and experimental data which was available for low Reynolds numbers. In a similar manner local flow calculations can be applied to compute the mass transfer rates between 

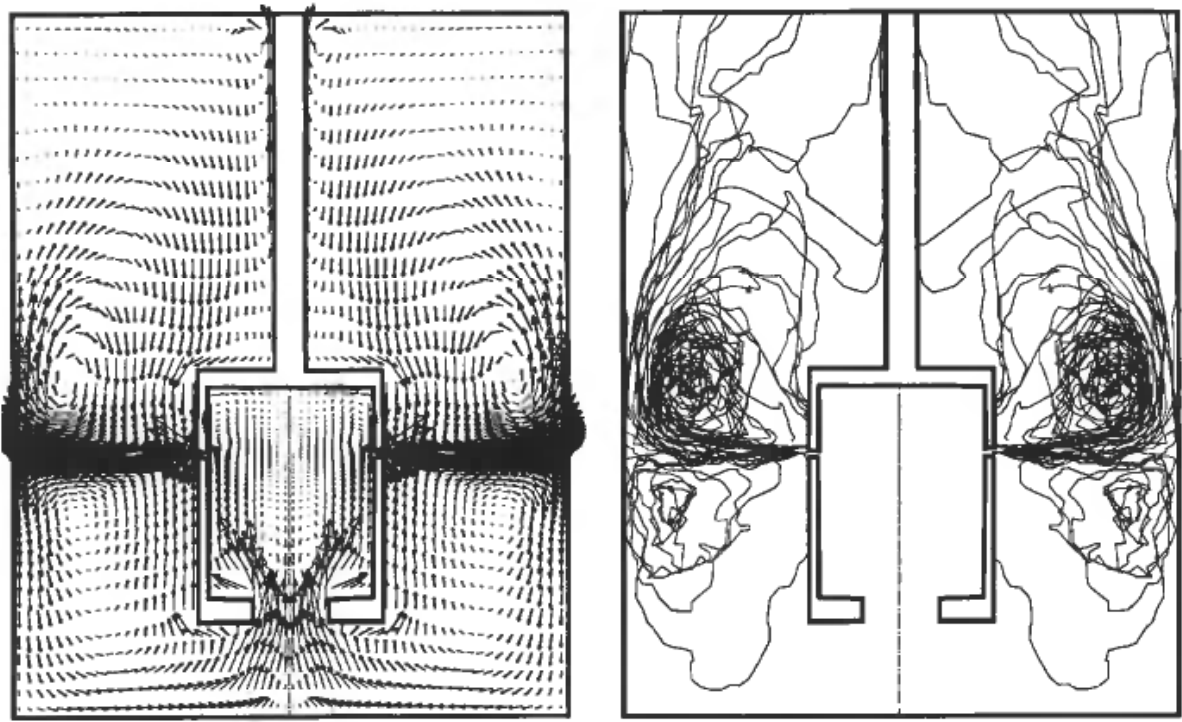

Figure 16. The predicted flow field for a $20 \mathrm{~cm}$ diameter "Hydro Aluminium Rotor" running at 600 RPM (left). The predicted dispersion of $0.4 \mathrm{~cm}$ diameter bubbles is shown.

Removal of 23 micron silicon carbide particles

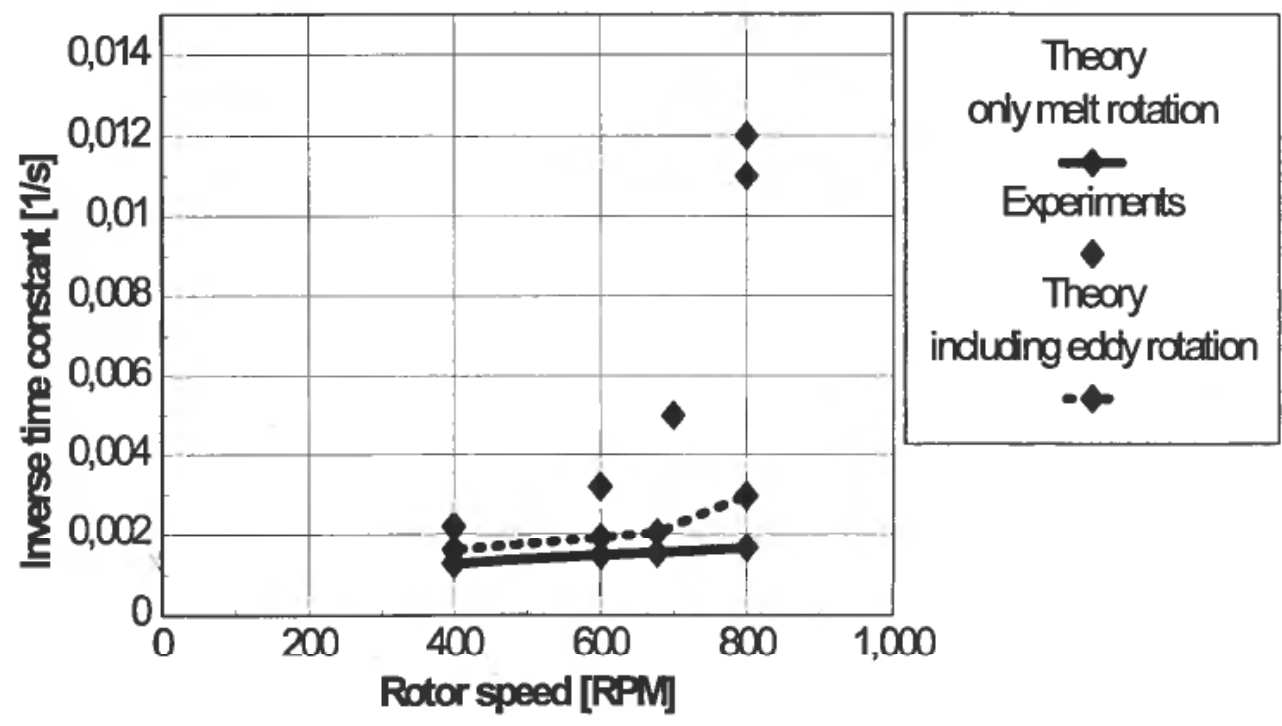

Figure 17. Comparison between experimental and predicted inverse timescales for inclusion removal, all versus rotor speed (Hop, Johansen and Rasch 1996).

bubbles and surrounding liquid. The CFD predictions are in good agreement with experimental data (Fredriksen 1995).

In melt refining the mass transfer across the top surface of the metal is of significant interest. In water models of such systems the mass transfer can be described quite well by CFD methods (Dong, Johansen and Engh 1992). However, due to the complex 

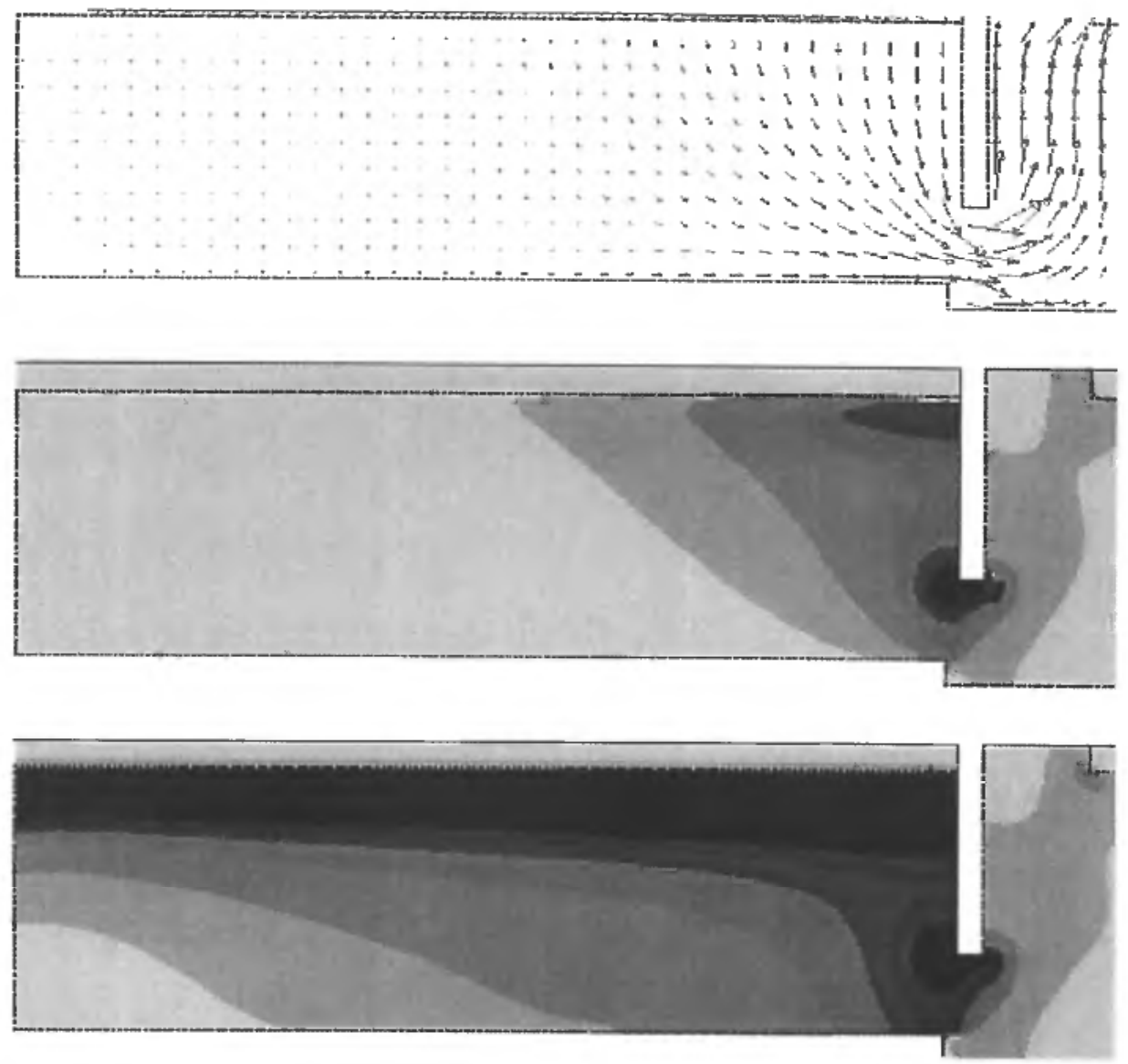

Figure 18. Predictions for the ALCOS 528 filter (Johansen and Anderson 1990). At the top we see the predicted velocity field, then the distribution of captured inclusion after 5 hours (in the middle) and after 97 hours (at the bottom).

interface structure in metallurgical systems quite a lot of theoretical development remains until reliable CFD approaches can be applied with full confidence.

In metal filtration for inclusion removal it is not obvious that CFD methods can be useful. However, we designed a model for flow and inclusion deposition in deep bed filters (Johansen and Anderson 1990). The model could deal with a spectrum of size classes and when inclusion particles had deposited inside the filter these particles became a part of the filter. The model was applied to the ALCOA 528 bed filter and showed that the flow through the filter made the shortest way possible during initial filtration. The particles deposited inside the filter, but after some time inclusion removal become more and more efficient close to the filter surface where metal entered the filter. The model predicted a true transition from deep bed filtration to surface or cake filtration. The predicted distribution of captured inclusions inside the filter is shown in Fig. 18. Later, experimental investigations in magnesium verified this phenomenon (Bakke 1992).

Often additions of alloying materials or grain refiners are added just before casting. The dissolution of particulate materials and the distribution of heat and dissolved materials is another good subject for CFD calculation. 
In order to study such phenomena we developed a transient Lagrangian model which could represent the size, temperature distribution inside particles as well as account for metal freeze at the particle surface. The particles were allowed to exchange both heat and momentum with the melt and in this manner influence both the flow-field and the temperature field (Gu, Hop and Johansen 1994).

\subsection{Casting of liquid metals}

The final area of applications we will like to discuss is flow phenomena occurring during casting of liquid metals. Solidification and free surface flows will often take place simultaneously. The combination of these phenomena in CFD-codes is not a trivial task, and in our group we are now working with developing numerical techniques which can handle the problems of interfacial mass transfer.

Since we in solidification problems have convection and turbulent transport of enthalpy and not temperature, we developed a numerical technique to overcome this problem (Johansen 1992). In this technique only an enthalpy equation is solved and the diffusive heat flux is formulated in terms of an enthalpy flux. Here temperature is calculated from a table, giving the temperature versus enthalpy. In Fig. 19 we see the prediction of the solidus surface and velocity vectors in a quarter section of a 2.00 $\times 0.60$ meter cross section aluminium ingot.

In casting problems involving free surfaces we have been working with the Volume-Of-Fluid techniques (VOF) (Hirt and Nichols 1981). The movement of interfaces is in this technique computed on a stationary grid solving the Eulerian conservation equation for the fluid volume fractions. The effects of surface tension and wetting angle can be accommodated by the continuous surface force technique (Brackbill, Kothe and Zemach 1992).

In Fig. 20 we have used this technique for predicting the flow and interface during initial filling of a mould. The domain shown in the figure has a height of $3 \mathrm{~mm}$ and a diameter of $120 \mathrm{~mm}$. The initial jet diameter is $6 \mathrm{~mm}$. From the dimensions of the figure it is easy to find that the boundary layer in the initially spreading film is extremely thin. Hence, the mass transfer and heat transfer can locally take extreme values. It can further be seen from the figure that a wave develops at some $40 \mathrm{~mm}$ radial position. This step in liquid height is in agreement with experimental observations and we believe it is initiated by the surface tension and the imposed wetting angle of $90^{\circ}$. Flows like this are extremely complex, and they are very difficult to analyse by analytical means.

\section{Conclusions}

From the examples given above it is obvious that computational fluid dynamics has a large range of applications. The applications have here been limited only to work done at SINTEF Materials Technology. Worldwide the activity in this field is vast and a large number of applications done by other groups are left out.

However, in spite of good merits, the application of CFD methods is not a guarantee of success or improved results compared to more standard approaches. The CFD methods will in general need the best possible theoretical formulations of the physics controlling the problem. In addition the CFD model has to be verified against experimental data before it can be used as a predictive tool. The experimental verification is crucial to the CFD model, which often can be much more complex than more standard models. The CFD model gives local informations for many quantities 

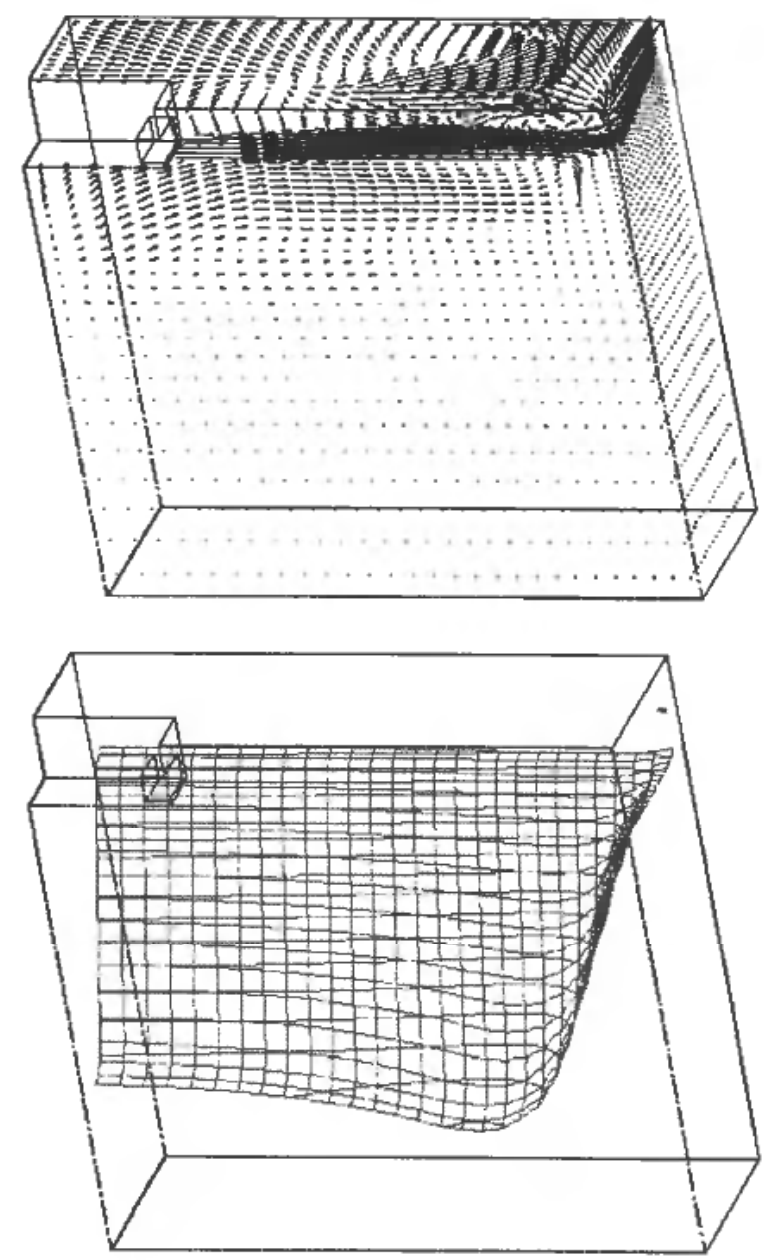

Figure 19. Casting of an aluminium ingot (quarter section). Upper: Predicted velocity vectors. Lower: Predicted surface for solidus temperature.

and in many positions at the same time. Hence, the increased spatial and temporal precision in the models leads to an increasing demand for experimental precision. Often it turns out that new experimental techniques have to be developed, as the CFD predictions bring into question quantities which previously was not measured.

In addition to the complexity of the models the numerical representation and solution of the transport equations makes CFD a field where impressive results may be obtained but disastrous results can just as well come out.

CFD is a tool which will be of major impact to the future development of metallurgical processes. However, such a development implies that the metallurgist working with CFD will need good knowledge in a large number of disciplines, including physics, chemistry, thermodynamics, fluid dynamics and numerical and experimental methods.

The complexity we are dealing with here makes it utterly important that the CFD software is well documented and that all important parts of the software is open to check 


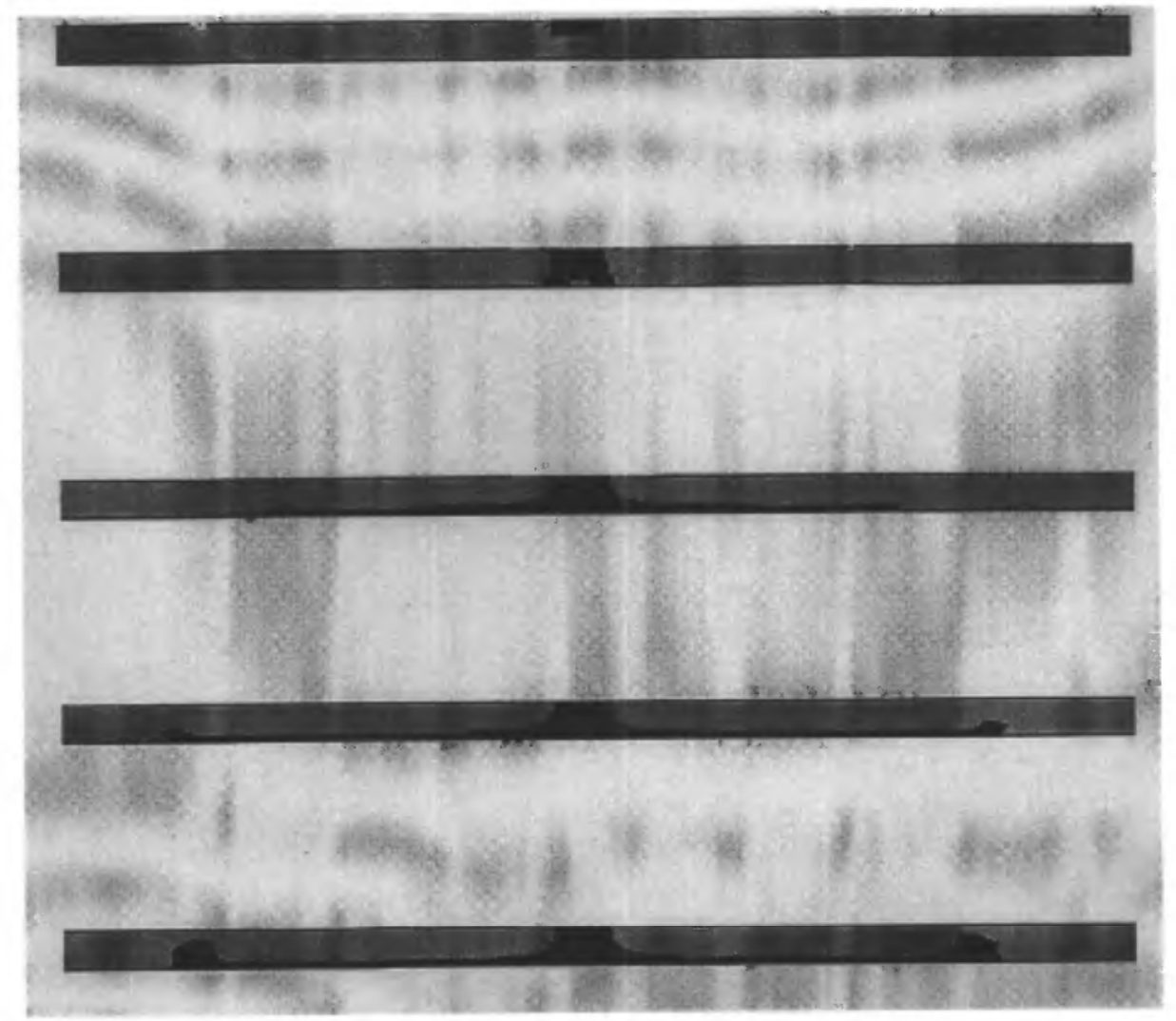

Figure 20. Predicted time series of surface positions for a jet of metal hitting a flat mould. Initial configuration at the top.

for the user. In this context CFD codes which come with closed code (object code) for the numerical implementation of the solver and the transport equations will hopefully not have a great future. Such closed codes will make the user dependant of the software supplier both in economical and technological terms. The trend in the commercial CFD software is today more advanced geometry representation, more models, better graphics but less information to the user about the numerical implementation. This last trend will not stop the fast development of CFD codes but will possibly open up for new vendors with a different market strategy.

The CFD methods are here to stay. They are today used to analyse more and more metallurgical phenomena and processes, and it is not drastic to claim that this will be the leading technique for design of metallurgical processes in the 21 st century.

\section{ACKNOWLEDGEMENTS}

The Norwegian Research Council, Norsk Hydro and Elkem have all contributed to this work which has been undertaken under a number of different research projects. Their support is highly appreciated. I am also grateful to all my colleagues who have contributed to this work. A special thanks to Dr H. Tveit, Elkem, who helped me proof-reading and who came with valuable suggestions to the exposition in this paper. 


\section{REFERENCES}

AARFlot, A. O., JohANSEN, S. T. and VenÅs, K. (1992). New in-line technology combining degassing and an efficient removal of non-metallic inclusions by gas fluxing. Proceedings of the 5th International Aluminium Extrusion Seminar, Vol. I, 155-160, May 19-22, Chicago.

ANDRESEN, B. (1995). Process model for carbothermic production of silicon metal. Ph.D.-thesis (The Norwegian Institute of Technology, Trondheim).

BAKKE, P. (1992). Measurement and removal of inclusions and hydrogen in magnesium. Ph.D.-thesis (The Norwegian Institute of Technology, Trondheim).

BOYSAN, F. and JOHANSEN, S. T. (1985). Mathematical modelling of gas-stirred reactors. International Seminar on Refining and Alloying of Liquid Aluminium and Ferro-Alloys, Trondheim, Norway, 267-288 (Aluminium-Verlag GmbH, Dusseldorf).

BRACKBILl, J. U., Kothe, D. B. and ZEMACH, C. (1992). A continuum method for modelling surface tension, J. Comput. Phys., 100, 335-354.

Crowe, C. T., Sharma, M. P. and Stock, D. E. (1977). The particle source in Cell (PSI-Cell) model for gas-droplet flows, J. Fluids Engr., 99, 235.

DONG, L., JOHANSEN, S. T. and ENGH, T. A. (1992). Mass transfer at gas-liquid interfaces in stirred vessels, Canadian Metallurgical Quarterly, 31, 299-307.

DONG, L., JOHANSEN, S. T. and ENGH, T. A. (1994). Flow induced by an impeller in an unbaffled tank-II. Numerical modelling, Chem. Eng. Sci., 49, 549-560.

ENSTAD, G. (1992). Private communication (POSTEC RESEARCH).

FREDRIKSEN, A. (1995). Strфmningsberegninger av varme- og masseovergang til bobler (SINTEF Report SF24 F95586).

GAMmelseter, R., JoHANSEN, S. T. and BergSTRøM, T. (1991). Modelling turbulent combustion with finite chemical kinetics, applied to furnace off gas combustion. Proceedings of the EDP Congress 1992. The TMS Annual Meeting, San Diego, CA. The Minerals, Metals \& Materials Society. 821-832.

GAMMELSÆTER, R. (1996). Private communication (SINTEF, Trondheim).

Gosman, A. D. and Launder, B. E. (1976). TEACH-2E, Internal report, Mech. Eng. Dept., Imperial College, London.

Gu, L. (1993) Transport phenomena in silicon vapour infiltrated Argon arcs and anodic metal pools. Ph.D.-thesis (The Norwegian Institute of Technology, Trondheim).

Gu, L., HoP, B. I. and JohANSEN, S. T. (1994). Modelling of dynamic oxide dissolution in aluminium reduction cells (SINTEF Report STF24 F94701).

HIRT, C. W. and NichOLS, B. D. (1981). Volume of fluid (VOF) method for the dynamics of free boundaries, J. Comput. Phys., 39, 201.

Holt, N. J. (1994). A metallurgical reactor with three plasma torches. Numerical simulation and experimental results. Ph.D.-thesis (The Norwegian Institute of Technology, Trondheim).

HOP, B. I., JOHANSEN, S. T. and RASCH, B. (1996). A 3D numerical model for removal of inclusions to gas bubbles, To appear in Light Metals (Anaheim).

JohANSEN, S. T. (1990). On the modelling of turbulent two-phase flows, Dr. Techn.-thesis (The Norwegian Institute of Technology, Trondheim).

JOHANSEN, S. T. (1991). Thermal-inertial deposition of particles. Proceedings of the International Conference on Multiphase Flows, 91-Tsukuba, Sept. 24-27, Japan, 415-421.

JoHANSEN, S. T. (1991). The deposition of particles on vertical walls, Int. J. Multiphase Flow, 17, 355-376.

JOHANSEN, S. T. (1992). A model for heat transport with phase transition where enthalpy is solved for directly (Unpublished research).

JOHANSEN, S. T. (1993). Sluttrapport: Groing av gasskanaler (SINTEF Report STF34 F93234).

JOHANSEN, S. T. (1994). A VOF (Volume of Fluid) technique for $3 D$ free surface flows. Presented at Fluid Mechanics in Heterogeneous Systems. Book of abstracts from the 7th Israeli-Norwegian Technical and Scientific Symposium, 50-52, The Norwegian Institute of Technology, June 20-22.

JOHANSEN, S. T. (1994). A general procedure for calculating 3D direct current MHD flows. Proceedings of the International Symposium on Electromagnetic Processing of Materials, Nagoya, ISIJ, 103-108.

Johansen, S. T., ANDERSON, N. M. and DE Silva, S. R. (1990). A two-phase model for particle 
local equilibrium applied to air classification of powders, Powder Technology, 63, $121-132$.

JOHANSEN, S. T., BOYSAN, F. and AYERS, W. H. (1987). Mathematical modelling of bubble driven flows in metallurgical processes, Applied Scientific Research, 44, 197-207.

JOHANSEN, S. T., BOYSAN, F. and ENGH, T. A. (1986). Numerical calculations of removal of inclusions and dissolution of refractory in bubble stirred ladles. Proceedings of the Fourth Japan-Nordic Countries Joint Symposium on Science and Technology of Process Metallurgy, Nov. 17-18, Tokyo, 182-215 (The Iron and Steel Institute, Japan).

Johansen, S. T., Fredriksen, A. and Rasch, B. (1995). Particle flotation to bubbles in rotor-stirred reactors for melt treatment. Light Metals, (Ed.) J. EVANS, TMS, 1203-1206.

Johansen, S. T., Graadahl, S., Gammelseter, R., RaAnes, M., ARnTSberG, A. E., LinSTAD, T., ENSTAD, G. and TVET, H. (1991). Clogging of ferro-silicon furnace off-gas channels at high temperatures (Smelter Process Gas Handling and Treatment) (Eds) T. J. A. SMITH and C. J. Newman. The Minerals, Metals \& Materials Society. 7-18.

JOHANSEN, S. T. and ANDERSEN, N. M. (1986). A model for predicting effects of thermophoresis on collection efficiencies in swirling flow precipitators (Gas Cleaning at High Temperatures), 73-88 (Pergamon Press).

JOHANSEN, S. T. and ANDERSON, N. M. (1990). A mathematical model for large scale filtration, EDP Congress '90, (Ed.) D. R. GAsKell. The Minerals, Metals \& Materials Society, $441-451$.

JOHANSEN, S. T. and BoysAN, F. (1988). Fluid dynamics in bubble stirred ladles, PART II: Mathematical modelling, Met. Trans. B, 19, 755-764.

JOHANSEN, S. T. and GU, L. (1994). A Reynolds stress turbulence model for fluid flow and enthalpy dispersion under influence of strong external magnetic fields. Proceedings of the International Symposium on Electromagnetic Processing of Materials, Nagoya, ISIJ, 49-54.

JOHANSEN, S. T. and LAUX, H. (1995). An alternative method for numerical solution of dispersed multiphase flow equations. Proceedings of The 2nd International Conference on Multiphase Flow 95-Kyoto, Vol. 2, NU-1, NU-8, April 3-7.

JOHANSEN, S. T. and DE SILVA, S. R. (1989). The use of computer models for the design of air classifiers. Proceedings of the Powder and Bulk Solids Conference, Chicago.

JOHANSEN, S. T. and DE SILVA, S. R. (1994). Some considerations regarding optimum flow fields for centrifugal air classification, 789-801. Preprints of the 8th European Symposium on Comminution, May 17-19, Stockholm.

Johansen, S. T., DE SILvA, S. R. and Vesanto, A. (1990). Multiphase turbulence modelling as a tool in the optimisation of classification equipment. Proceedings of the Second World Congress Particle Technology, Vol. III, 135-142, Sept. 19-22, Kyoto, Japan.

Larsen, H. L., Hildal, A., Sevastyanenko, V. G. and Bakken, J. A. (1995). Numerical modelling of AC electric arcs. Proceedings of the 12th International Symposium on Plasma Chemistry, Aug. 21-25 1995, University of Minnesota. 2339-2344. (Eds) J. V. HEgERLEIN, D. W. ERNIE and J. T. ROBERTS.

LAUNDER, B. and SPALDING, D. B. (1972). Mathematical models of turbulence (Academic Press, London).

LaUX, H. (1997). Ph.D.-thesis. To be completed during 1997 (NTNU, Trondheim).

PATANKAR, S. V. (1980). Numerical heat transfer and fluid flow (Hemisphere Books).

SOlHEIM, A., JohANSEN, S. T., RolseTH S. and THONSTAD, J. (1989). Gas induced bath circulation in aluminium reduction cells, Joumal of Applied Electrochemistry, 19, 703-712.

VENÅS, K. and JOHANSEN, S. T. (1986). A new centrifuge for cleaning dusty gases at temperatures below 500 degrees C (Gas Cleaning at High Temperatures), 133-148 (Pergamon Press). 